\title{
Quarantine and COVID-19
}

\author{
${\text { Michelle Odalys Flores Barriguete }{ }^{1 *} \quad \text { Sepideh Alasvand Zarasvand }}^{2}$ \\ 1.El Pasoans Fighting Hunger Food Bank, El Paso, Texas, USA School of Economics, Peking \\ 2. Department of Food, Nutrition and Packaging Science, Clemson University, Clemson, South Carolina, USA
}

\begin{abstract}
The COVID-19 pandemic which have affected every part of the world have been deemed a public health concern and classified as a pandemic. The government imposing travel bans and quarantine measures have been found to be effective in preventing and reducing the spread of COVID-19. A reduction in physical activity and increase in the consumption of unhealthy foods have been observed to be some of the major implications of quarantine. Adequate physical activity and increased access to healthy foods would help in improving the psychological wellbeing of individuals thereby preventing the development of cardiovascular diseases.
\end{abstract}

Keywords: Quarantine; COVID-19; Physical activity

DOI: $10.7176 / \mathrm{JHMN} / 85-11$

Publication date: January $31^{\text {st }} 2021$

\section{Quarantine and COVID-19}

The coronavirus disease 2019 (COVID-19) caused by severe acute respiratory syndrome coronavirus 2 (SARSCoV-2) have achieved a pandemic status [1]. SARS-CoV-2 is a single stranded ribonucleic acid (RNA) virus like the severe acute respiratory syndrome coronavirus (SARS-CoV) and Middle East respiratory syndrome corona virus (MERS-CoV) from 2002 and 2012, respectively. [1,2] These coronaviruses have been observed to have originated from bats because they share a high percentage of nucleotide identity with bat coronaviruses. The primary mode of SARS-CoV-2 transmission is via respiratory droplets or human-to-human contact. $[2,3,4]$ Quarantine measures and travel bans have been put in place by the government of several countries as a form of preventive measure to reduce the spread of COVID-19 among its residents. The term quarantine refers to separating individuals or groups that have been exposed to communicable diseases. [5,6] While quarantine has been effective in slowing the spread of COVID-19, it has also affected the lifestyle of people. A decrease in physical activity and increase in intake of unhealthy diet among people have been observed during quarantine. $[5,7]$

As COVID-19 pandemic progresses, people are forced to stay indoors. Lockdown measures imposed by the government on businesses and recreation centers have compelled people to work from home or perform daily exercise in their homes. This has led to a reduction in physical activity. Inadequate or a complete lack of physical activity has been linked to the development of obesity and/or cardiovascular diseases which could be life threatening. [8,9] Increased intake of unhealthy diet as well as poor nutrient intake has been observed to be a direct consequence of quarantine. People are consuming more fast foods, processed foods, frozen foods and ready to eat foods which are mostly unhealthy. [8,11] There has been a considerable reduction in fruits and vegetables consumption which is known to have a high antioxidant content which protects the body against free radicals, preventing the development of heart diseases. Strenuous quarantine measures have also been researched and found to trigger binge eating episodes in some people. $[10,13]$ Lots of grocery stores have reduced the number of people allowed in stores at a particular period, stores have started closing earlier than usual resulting in a reduction in access to food.

Quarantine have also been studied to have a negative psychological effect on the overall wellbeing of individuals. People who have been quarantined or currently undergoing quarantine have reported experiencing one or more of the following: worries, insomnia, lack of concentration, petulance, and unwillingness to work.[12] Lack of food and water have been linked to anxiety or frustration in some people even months after quarantine release. $[14,15,16]$ In conclusion, increasing physical activity would help improve overall health resulting in a positive effect on the psychological wellbeing of individuals during quarantine. Lifestyle changes such as a change in food intake from processed and unhealthy foods to healthy foods, fresh fruits and vegetables would aid in boosting immune and antioxidant function preventing the development of cardiovascular diseases.

\section{References}

[1] Esobi, I. C., Lasode, M. K., Anyanwu, C. I., Degbe, E., Barriguete, M. F., Okorie, M. A., ... \& Okegbe, S. (2020). Nutritional Impact of COVID-19 and Its Implications on Atherosclerosis. World, 8(1), 16-21.

[2] Clerkin, K. J., Fried, J. A., Raikhelkar, J., Sayer, G., Griffin, J. M., Masoumi, A., ... \& Schwartz, A. (2020). COVID-19 and cardiovascular disease. Circulation, 141(20), 1648-1655.

[3] Wang, D., Hu, B., Hu, C., Zhu, F., Liu, X., Zhang, J., ... \& Zhao, Y. (2020). Clinical characteristics of 138 hospitalized patients with 2019 novel coronavirus-infected pneumonia in Wuhan, China. Jama, 323(11), 
1061-1069.

[4] Esobi, I.C., Lasode, M.K., \& Barriguete, M.O.F. (2020). The Impact of COVID-19 on Healthy Eating Habits. J Clin Nutr Heal, 1(1), 001-002.

[5] Parmet, W. E., \& Sinha, M. S. (2020). Covid-19- the law and limits of quarantine. New England Journal of Medicine, 382(15), e28.

[6] Lasode, M., Esobi, I., Anyanwu, C., \& Lasode, D. (2020). Assessing Urban Land use Change in New Braunfels, Texas from 2013 to 2020.

[7] Oluwaseun, O., Tolulope, F., Lukuman, B., \& Ikechukwu, E.C. (2020). Improving Pre-service Teachers' Memory and Retention Using Durable Memory Strategies in an Instructional Technology Course. American Journal of Educational Research, 8(11), 847-855.

[8] Mattioli, A. V., Puviani, M. B., Nasi, M., \& Farinetti, A. (2020). COVID-19 pandemic: the effects of quarantine on cardiovascular risk. European Journal of Clinical Nutrition, 1-4.

[9] Abimbade, O., Akinyemi, A., Bello, L., \& Olusegun, M. (2018). Comparative effects of an individualized computer based instruction and a modified conventional strategy on students' academic achievement in organic chemistry. The Journal of Positive Psychology and Counselling.

[10] Fernández-Aranda, F., Casas, M., Claes, L., Bryan, D. C., Favaro, A., Granero, R., ... \& Menchón, J. M. (2020). COVID-19 and implications for eating disorders. European Eating Disorders Review, 28(3), 239.

[11] Esobi, I. C., Lasode, M. K., Anyanwu, C. I., Barriguete, M. F., Okorie, M. A., \& Lasode, D. O. Food Insecurity, Social Vulnerability, and the Impact of COVID-19 on Population Dependent on Public Assistance/SNAP: A Case Study of South Carolina, USA.

[12] Brooks, S. K., Webster, R. K., Smith, L. E., Woodland, L., Wessely, S., Greenberg, N., \& Rubin, G. J. (2020). The psychological impact of quarantine and how to reduce it: rapid review of the evidence. The Lancet.

[13] Abimbade, O., Adedoja, G., Fakayode, B., \& Bello, L. (2019). Impact of mobile-based mentoring, socioeconomic background and religion on girls' attitude and belief towards antisocial behaviour (ASB). British Journal of Educational Technology, 50(2), 638-654.

[14] Jeong, H., Yim, H. W., Song, Y. J., Ki, M., Min, J. A., Cho, J., \& Chae, J. H. (2016). Mental health status of people isolated due to Middle East Respiratory Syndrome. Epidemiology and health, 38.

[15] Oluwadara, A., Kolapo, B. L., \& Esobi, I. C. (2020). Designing a Framework for Training Teachers on Mobile Learning in Sub-Sahara Africa.

[16] Esobi, I. C., Lasode, M. K., \& Barriguete, M. F. Journal of Clinical Nutrition and Health. 